\title{
Seismogenic fault and tectonic significance of 1996 Karakoram Pass earthquake (Ms 7.1) based on InSAR
}

\author{
Jiangtao Qiu* (0), Lingyun Ji, Lei Liu and Chuanjin Liu
}

\begin{abstract}
Due to hard observation condition of the western Tibet region, the slip behaviors of the Ms7.1 Karakoram Pass earthquake occurred in Hetian, Xinjiang on November 19, 1996 remains unclear. Using ERS 1/2 SAR data and InSAR technique, we obtain the co-seismic deformation of the earthquake. The north and south deformation areas show asymmetric pattern, with the maximum LOS displacement of the southern part approximately $24.6 \mathrm{~cm}$, and the maximum LOS displacement in the northern part approximately $-18.5 \mathrm{~cm}$. Nonlinear and linear inversion algorithms are used to determine the geometric parameters and slip distribution of the earthquake fault. Our results show that the co-seismic displacement is dominated by deformation fields are clearly visible sinistral strike-slip accompanied by a small amount of normal slip component. The co-seismic slip occurred between 0 and $18 \mathrm{~km}$ at depth. The maximum slip is $\sim 81 \mathrm{~cm}$, occurring at a depth of $8.5 \pm 0.5 \mathrm{~km}$ at $\left(35.36^{\circ} \mathrm{N} 78.03^{\circ} \mathrm{E}\right)$, indicating a shallow event with a moment magnitude of Mw 6.5. The seismogenic fault is a secondary fault in the Karakoram fault zone with strike $96^{\circ}$, dip $84^{\circ}$, and rake $-24^{\circ}$. This earthquake shows that the Karakoram fault zone undergoes a complex tectonic deformation process, with central part of the fault zone showing minor tensional deformation behaviors.
\end{abstract}

Keywords: Karakoram Pass earthquake, InSAR, Co-seismic deformation, Seismogenic fault, Slip distribution

\section{Introduction}

On November 19, 1996, at 18:44 CST, an earthquake with a surface-wave magnitude of $7.1\left(M_{\mathrm{s}}\right)$ occurred in the Karakoram Pass region, just southwest of Hetian, Xinjiang (hereinafter referred to as the Karakoram Pass earthquake). This strong earthquake, which resulted in multiple slope collapses and landslides, was the first strong earthquake to occur in this region since the formation of a seismic gap region $(M \geq 4)$ in October 1980 (Luo et al. 2003), indicating active crustal movement in the northwest part of the Qinghai-Tibetan Plateau. Various institutions have provided focal mechanism solutions for this event, all of which show that this earthquake was mainly a strike-slip rupture event. However, because this earthquake occurred in an area where the coverage of the seismic network is very limited, the seismogenic

*Correspondence: jiangtao_q@sina.com

The Second Monitoring and Application Center, China Earthquake Administration, Xi'an 710054, China structures provided by the different institutions varied significantly (Table 1). Ge (1997) provided a focal mechanism solution based on the GCMT, where it was proposed that the seismogenic fault should be a secondary transverse fault related to the Karakoram fault. Luo et al. (2003) proposed that the Linjitang fault in the Karakoram fault zone was a seismogenic fault.

The Karakoram Pass earthquake occurred in an uninhabited region (elevation $>5 \mathrm{~km}$ ) characterized by harsh environment and dangerous roads, where conducting field geological surveys and traditional deformation measurements is extremely difficult. As a result, very few studies have focused on the seismogenic structure and deformation caused by this earthquake. More importantly, an in-depth analysis of the tectonic implications of this event is still lacking. An increasing number of scholars regard interferometric synthetic aperture radar (InSAR) technology as an important tool for studying seismic deformation in remote areas. InSAR has been successfully used for seismic studies in the 
Table 1 Focal mechanism solutions for the Karakoram Pass earthquake provided by various institutions

\begin{tabular}{llllll}
\hline Institution & $\begin{array}{l}\text { Epicenter }\left(^{\circ}\right) \\
\text { Latitude, longitude }\end{array}$ & Magnitude & Depth $(\mathbf{k m})$ & $\begin{array}{l}\text { Nodal plane 1 }\left(^{\circ}\right) \\
\text { Strike, dip, rake }\end{array}$ & $\begin{array}{l}\text { Nodal plane 2 }\left(^{\circ}\right) \\
\text { Strike, dip, rake }\end{array}$ \\
\hline GCMT & $35.45,77.86$ & $M_{w} 6.8$ & 15.0 & $180,71,170$ & $273,81,19$ \\
USGS & $35.345,78.133$ & $M_{w} 6.8$ & 33.0 & $90,87,-7$ & $180,83,-177$ \\
Gao et al. (2005) & $35.26,78.21$ & $M_{\mathrm{s}} 7.1$ & 16.0 & $10,70,174$ & $106,80,6$ \\
This paper & $35.36,78.03$ & $M_{\mathrm{w}} 6.5$ & 8.3 & $96,84,-24$ & None \\
\hline
\end{tabular}

GCMT Global Centroid Moment Tensor Project, USGS United States Geological Survey

Qinghai-Tibetan Plateau and the surrounding regions (Ji et al. 2017; Zhao et al. 2017; Qiu and Qiao 2017; Wen et al. 2015; Teshebaeva et al. 2014; Sun et al. 2007). Using InSAR and ERS-1/2-SAR (C-band) data provided by the European Space Agency (ESA), the co-seismic surface deformation field of the 1996 Karakoram Pass earthquake was obtained in the present study. Quantitative inversion analysis based on Okada's theory of dislocation was used to determine the seismic fault's geometric parameters and slip distribution (Okada 1985). The aim of the present paper is to investigate the causes and mechanisms of shallow earthquakes in the Karakoram fault zone and to broaden our understanding of the impact of the Karakoram Pass earthquake on the pattern of strong seismic activity in the Qinghai-Tibetan Plateau.

\section{Regional tectonic background}

The collision between the Indian and Eurasian plates due to their continuous convergence has led to strong intracontinental deformation in Central Asia, giving rise to intense tectonic activity in the Pamir Plateau and the surrounding regions (Pan et al. 2009; Li et al. 2006). The main bodies of the Karakoram and Kunlun Mountains in the West Kunlun tectonic zone are characterized by continuous uplift. A series of Quaternary tectonic structures have developed in this region, most of which have been especially active since the Late Pleistocene. These tectonic structures determine the distribution of seismic belts and the intensity of modern seismic activity. Among these, the Taxkorgan fault zone, Kongur fault, Kangxiwa fault, Kegang fault, and Karakoram fault are the most representative structures (Chen 2008). The Karakoram fault has an overall length of $510 \mathrm{~km}$. It forms a huge conjugate fault zone with the adjacent left-lateral Altyn Tagh fault, which controls the direction of neo-tectonic movement along the northwest margin of the Qinghai-Tibetan Plateau.

The early-period deep Karakoram ductile shear zones are distributed on the southwest side of the late-period Karakoram fault zone, jointly forming the dextral strike-slip Karakoram fault zone with an overall strike of N45 ${ }^{\circ} \mathrm{W}$ (Searle et al. 1998; Valli et al. 2007). Due to the nearly $\mathrm{N}-\mathrm{S}$ compressive stress, the cumulative displacement of the Karakoram fault zone has reached at least $280 \mathrm{~km}$, whereas its average long-term slip rate is at least $10 \mathrm{~mm}$ /year. (Li et al. 2006, 2008; Matte et al. 1996). Using 2576 GPS velocities of the Indo-Asian continent from 1999 to 2017, Zheng et al. (2017) calculated the dextral strike-slip rate of the Karakoram fault at $\sim 77^{\circ} \mathrm{E}, \sim 79^{\circ} \mathrm{E}$, and $\sim 81^{\circ} \mathrm{E}$ to be $6.0 \pm 1.5 \mathrm{~mm} /$ year, $3.8 \pm 2.5 \mathrm{~mm} /$ year, and $3.2 \pm 2.3 \mathrm{~mm} /$ year, respectively. In addition, the $\sim 77^{\circ} \mathrm{E}$ and $\sim 81^{\circ} \mathrm{E}$ sites had a crustal shortening rate of $5 \pm 1.5 \mathrm{~mm} /$ year and $0.5 \pm 2.5 \mathrm{~mm} /$ year, respectively, whereas the $\sim 79^{\circ} \mathrm{E}$ site had an extension rate of $3.3 \pm 2.5 \mathrm{~mm} /$ year.

The Ms 7.1 Karakoram Pass earthquake struck in the Mesozoic continental-margin basin in the Karakoram fault zone (Fig. 1). This was the strongest earthquake to occur in this fault zone since 1976. The Mesozoic continental-margin basin of the Karakoram fault zone was uplifted during the Neogene. It formed into NW-oriented compressionshear faults and tight linear folds after multiple periods of tectonic movement (Pan et al. 2013). The Linjitang fault in the basin forms the boundary between the anticlinal fold belt of the South Kunlun Mountains and the Linjitang depression. The Ageledaban fault is a normal crustal fault, which has displayed strong activity in the Late Paleozoic, Mesozoic, and Cenozoic (Luo et al. 2003). The earthquake epicenter was at the location of China's maximum gravity value. Its measured Bouguer anomaly was approximately $-500 \mathrm{mGal}$ and the measured isostatic gravity was -180 mGal (Xu et al. 2014). Based on geodetic leveling data acquired from 1955 to 1995, the uplift rate in the epicenter area before the Karakoram Pass earthquake was $4-5 \mathrm{~mm} /$ year (Wang et al. 2009).

\section{InSAR co-seismic deformation field acquisition SAR data acquisition and processing}

The number of SAR images available for the Karakoram Pass earthquake is very limited. A total of 4 images were downloaded from the ERS 1/2 data catalog published by 


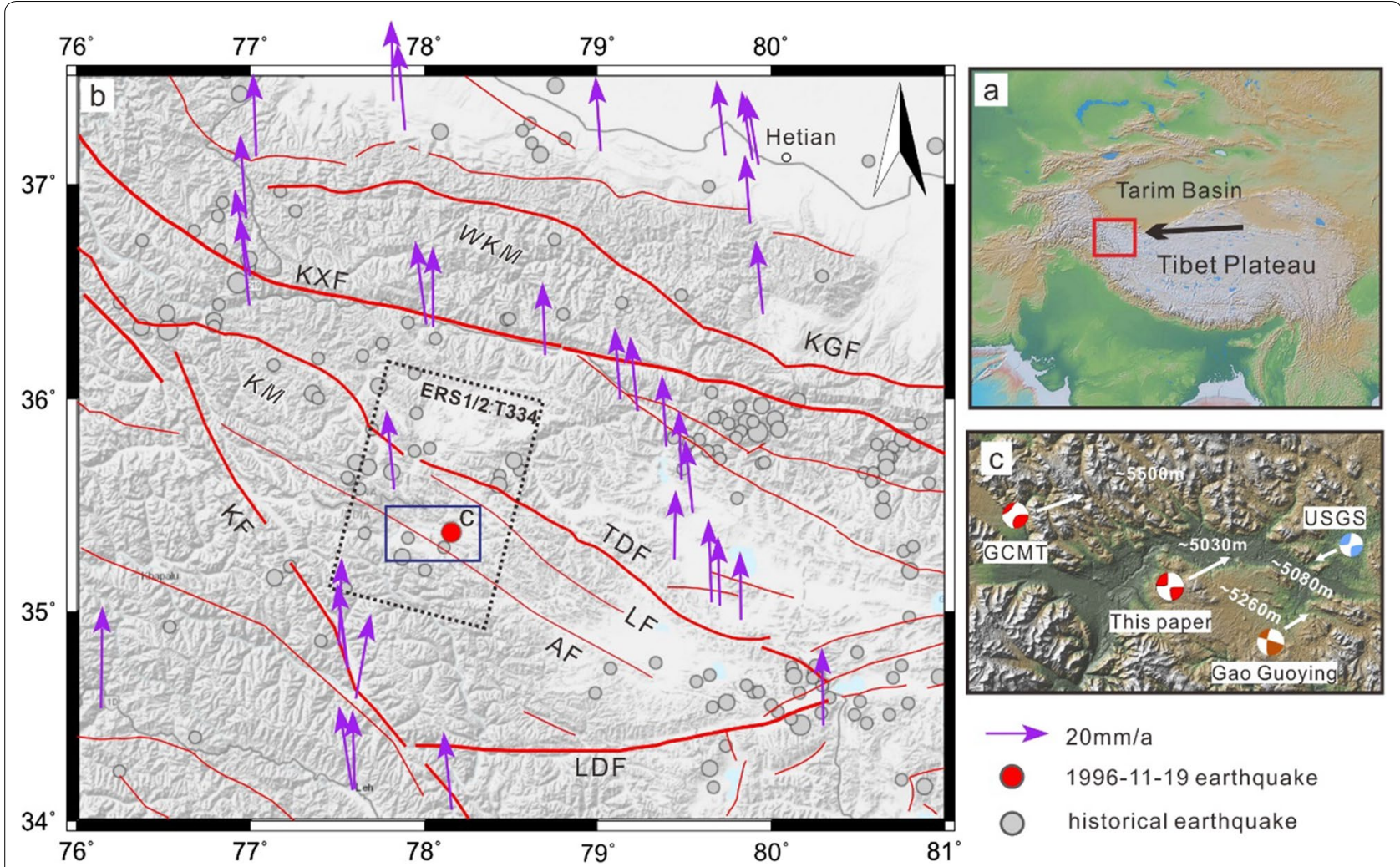

Fig. 1 Location and regional tectonic background of the 1996 Karakoram Pass earthquake. The red dot is the earthquake epicenter, the red lines are traces of faults from Central Asia Fault Database, and the purple arrows show the GPS velocity from Zheng et al. (2017). a is a topographic map, the red box is the range of $\mathbf{b}, \mathbf{c}$ is a detailed topographic map near the earthquake. WKM West Kunlun Mountains, KM Karakoram Mountains, KXF Kangxiwa fault, KGF Kegang fault, TDF Tianshendaban fault, LF Linjitang fault, AF Ageledaban fault, KF Karakoram fault, LDF Longmu-Dulishi fault

the ESA. Table 2 and Fig. 2 show detailed image pairing data.

Due to the low vegetation coverage in the QinghaiTibetan Plateau, the multi-path scattering effect caused by vegetation is minimal in this region. To minimize the loss of coherence due to topographic errors or image distortion, NASA's 30-m SRTM DEM data and the ERS Precise Orbit data provided by Delft University, Netherlands are used to perform two-pass differential interferometry (Massonnet et al. 1995) using the advanced radar image processing software ENVI/ SARscape. Figure 3 shows a data processing flow chart.
The robust Goldstein filtering method was used to ensure the clarity of fringes and reduce coherence loss due to noise from the spatial and temporal baselines (Goldstein and Werner. 1998). Due to the presence of large areas of low coherence and incoherence, phase unwrapping based on the minimum cost flow method was used to mask any pixels with coherence below a selected threshold (Ghiglia and Romero 1994; Liu et al. 2018). Because the spatial and temporal baselines of the interferometric image pairs were relatively long, the obtained interferograms still contained some phase noise caused by residual orbital errors, despite the use

Table 2 Information for pairing InSAR images(trace number: 334, frame number: 2889)

\begin{tabular}{|c|c|c|c|c|c|}
\hline Master image (satellite) & Slave image (satellite) & $\begin{array}{l}\text { Time baseline } \\
\text { (days) }\end{array}$ & $\begin{array}{l}\text { Perpendicular } \\
\text { baseline }(\mathrm{m})\end{array}$ & $\begin{array}{l}\text { Doppler centroid } \\
\text { diff. }(\mathrm{Hz})\end{array}$ & $\begin{array}{l}\text { Master image } \\
\text { incident angle } \\
\left({ }^{\circ}\right)\end{array}$ \\
\hline 19960418 (ERS2) & 19990513 (ERS2) & 1120 & 46.078 & -5.707 & 23.122 \\
\hline 19960522 (ERS1) & 19990513 (ERS2) & 1086 & 467.958 & 226.517 & 23.258 \\
\hline 19960522 (ERS1) & 19980910 (ERS2) & 841 & -56.212 & 202.136 & 23.258 \\
\hline
\end{tabular}


Time Interval (days)

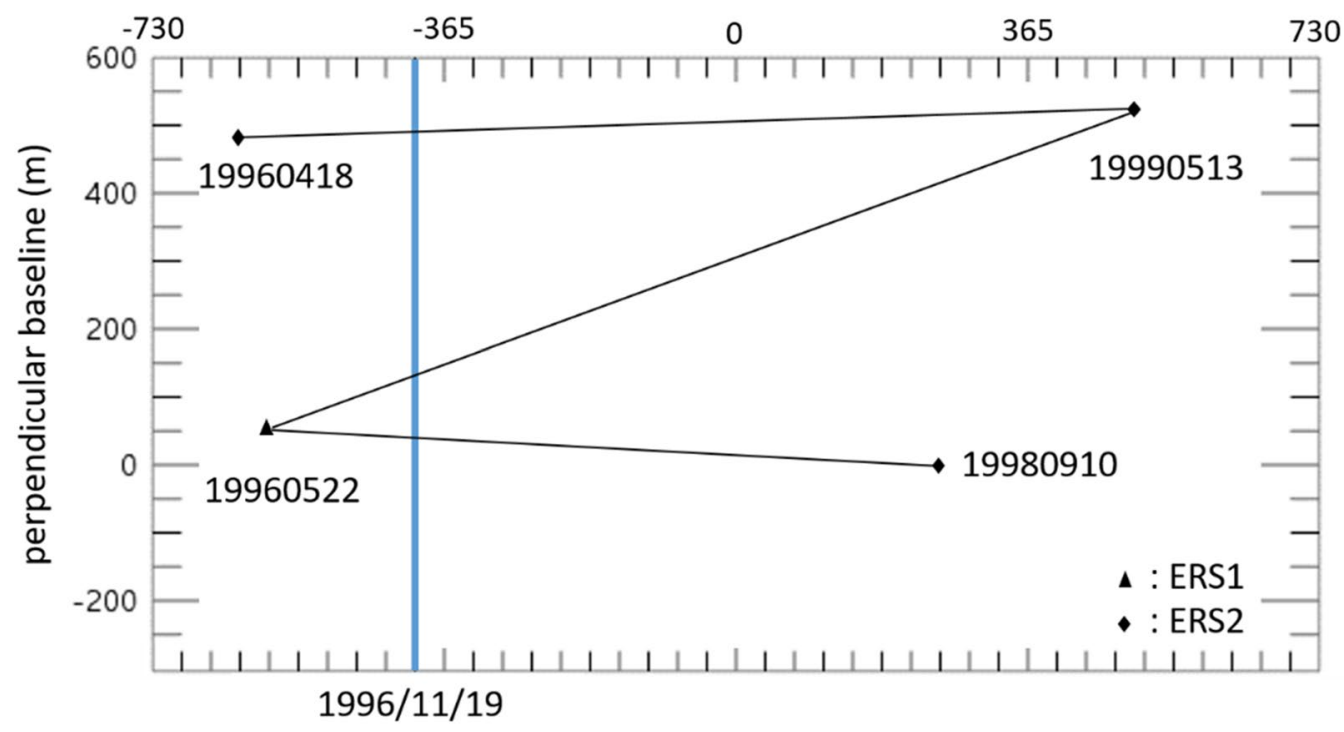

Fig. 2 InSAR image pair baselines

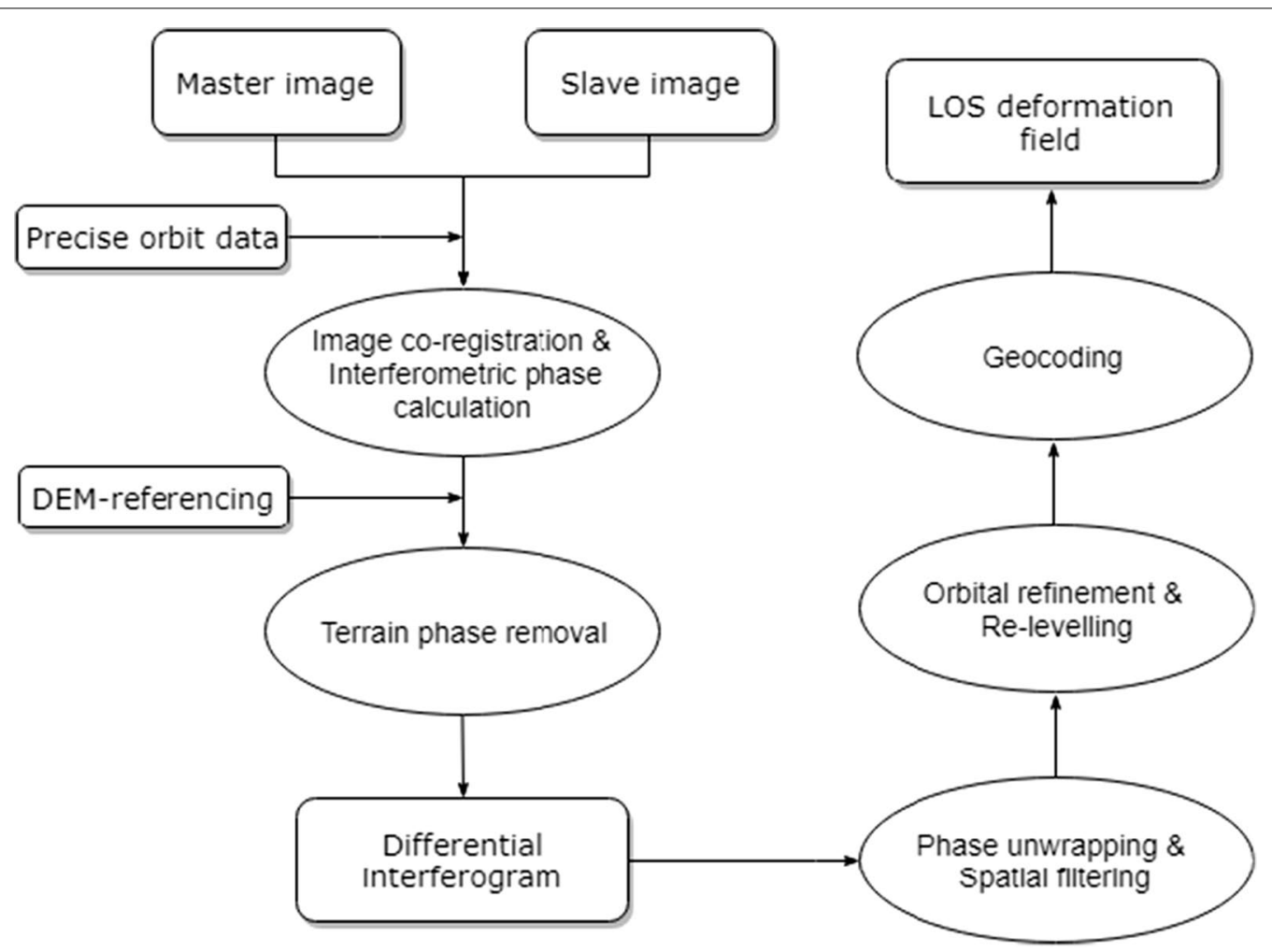

Fig. 3 InSAR image processing flowchart

of precise ephemeris data. To reduce this effect, polynomial model-based orbital refinement and phase shift correction were applied using multiple ground control points (GCPs) located far from the deformation region in open and flat areas, such as river valleys. Finally, after clipping and geocoding, we obtain the co-seismic surface deformation field produced by the Karakoram Pass earthquake (Fig. 4). 


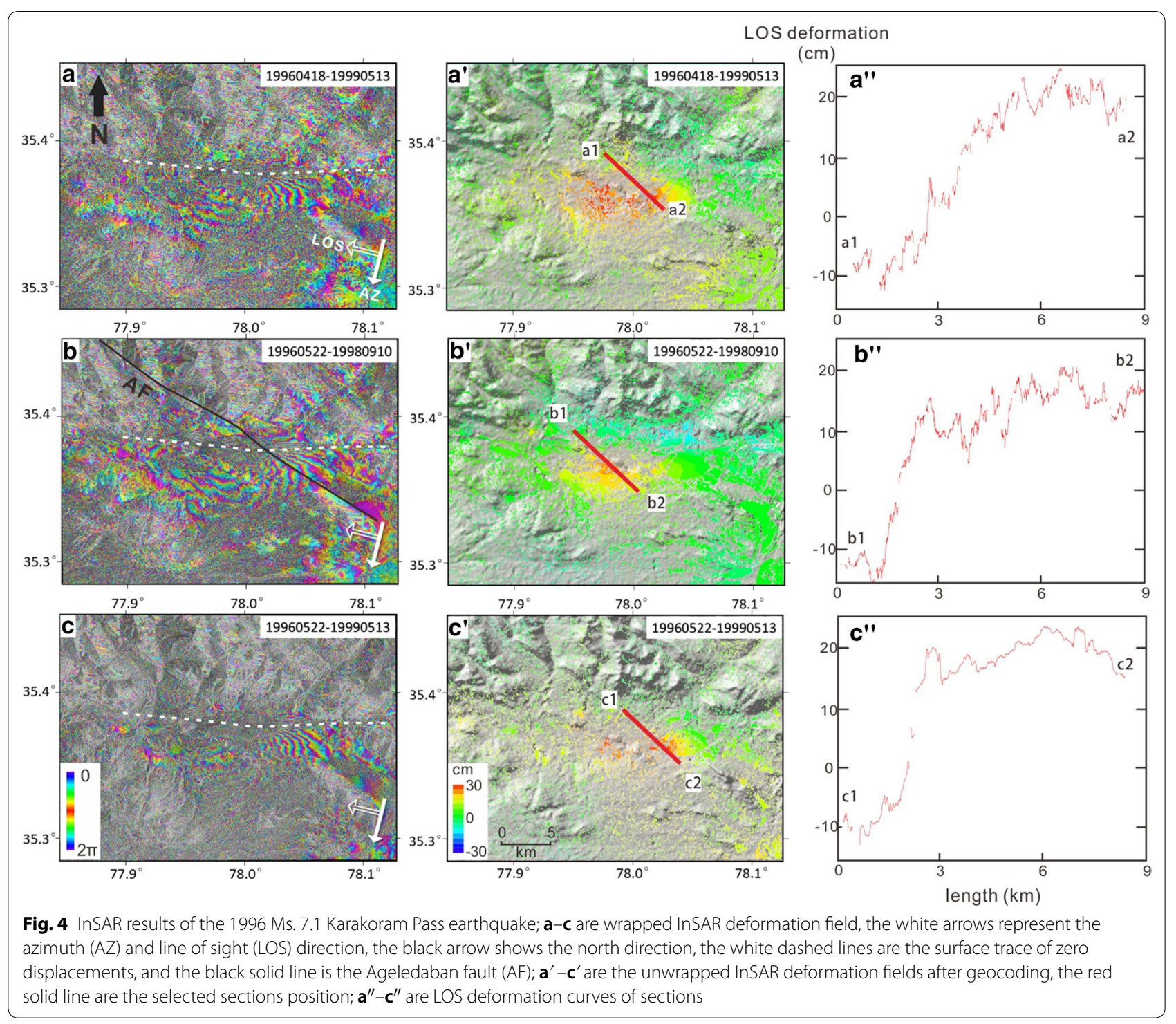

The location of the Karakoram Pass earthquake is the Depsang basin, where melting alpine snowpack and long-time intervals between paired images directly affect the coherence of the interferograms. High coherence could only be obtained in flat regions, such as basins and valleys (coherence coefficient above 0.5 ).

\section{InSAR co-seismic deformation}

It is evident from the InSAR interferograms in Fig. $4 a-c$ that the fringes from the three deformation fields are clearly visible. Deformation along the (LOS) direction for each fringe period is $2.8 \mathrm{~cm}$, and most deformation is concentrated within an area measuring $18 \times 9 \mathrm{~km}^{2}$. The surface deformation caused by the Karakoram Pass earthquake presents two deformation areas (north and south) centered on an E-W strike fault. The strike angle of this fault is approximately $96^{\circ}$, which is consistent with nodal plane 1 of the focal mechanism solution provided by USGS. In addition, this fault cuts across the Ageledaban fault. However, it is presumed to be a concealed secondary fault (white dashed line in Fig. 4) because its structure is not clearly visible on the surface.

The north and south deformation areas are clearly asymmetric. It is evident from the periodic changes in the deformation fringes shown in Fig. 4 that the fringes on the north side of the concealed fault are tightly spaced without an obvious diversion trend, indicating the earthquake caused large deformation within a very narrow area. In contrast, the fringes on the south side are half-elliptical and diverge along the southeast direction, consistent with sinistral shear trend. Because SAR produces side-looking images, the co-seismic 
deformation fields were obtained along the LOS direction. In addition, positive LOS deformation value after geocoding with ENVI/SARscape indicates that the surface was approaching the satellite (e.g., uplift), whereas a negative value indicates that the surface was moving away from the satellite (e.g. subsidence). The three deformation profiles in Fig. $4 \mathrm{a}-\mathrm{c}$ indicate the area north of the fault was moving away from the satellite during the two imaging periods, on the contrary, the area south of the fault was moving toward the satellite. Consequently, one can conclude that the deformation field reflects sinistral strike-slip fault activity, also shown in Wang and Wright (2012).

The maximum LOS displacement in the southern side is approximately $24.6 \mathrm{~cm}$, and the maximum LOS displacement in the northern side is approximately $-18.5 \mathrm{~cm}$. The maximum deformation area is located at the intersection of the concealed fault and the Ageledaban fault.

\section{Fault source modeling}

Fault-geometry parameters provide one of the primary bases for understanding co-seismic deformation. Therefore, we invert the InSAR data for estimating the coseismic slip distribution of the Karakoram Pass earthquake in two steps. First, we performed an exhaustive search for the best-fit fault parameters under the assumption of uniform slip on a rectangular fault. Then, we divided the faults into sub-faults and estimated the slip along each fault patch.

To reduce the number of points and consequently improve the computational efficiency, we first attempted to down-sample the InSAR data using the quadtree partitioning method (e.g., Ji et al. 2017). However, this failed to capture the primary deformation pattern with a sufficiently high resolution. We subsequently grid-sampled the near-field area at a dense regular spacing and the farfield area at a sparse regular spacing. The deformation fields (Fig. 4a-c) are downsampled. Finally, we obtained 1315 points for inversion, including 436 from Fig. 4a, 598 from Fig. 4b and 281 from Fig. 4c, and all the three data are combined in one figure (Fig. 5).

\section{Inversion of fault parameters}

Okada (1985) showed that the causative fault can be interpreted as one rectangular plane with a uniform slip embedded within a homogeneous, isotropic, elastic halfspace. Therefore, using the InSAR surface displacements, we can potentially place constraints on the fault parameters through modeling (Kobayashi 2017).

We use the focal mechanism solution published by USGS as the initial input, the parameters of the fault (latitude, longitude, strike, dip, rake, slip, fault depth, length,

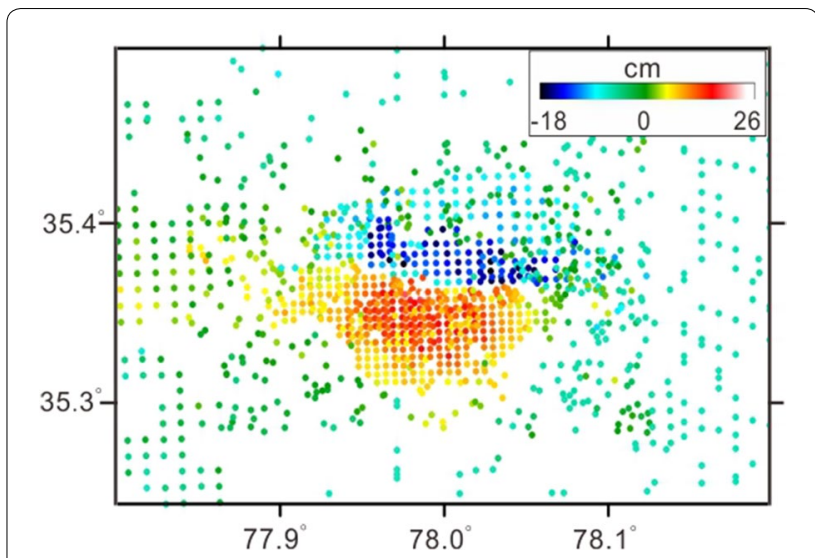

Fig. 51315 observed values for inversion of the co-seismic deformation field

and width) were solved iteratively using the LevenbergMarquardt least squares optimization algorithm (Marquardt 1963). Using repeated iterations allows redundant parameters to be eliminated, thereby ensuring that the cost function converges to a global minimum.

As shown in Table 3, the strike of the fault is approximately east-west (EW) at an angle of $96^{\circ}$ and with a dip of $84^{\circ}$. These fault parameters are quite consistent with those provided by USGS for nodal plane 1 in the focal mechanism solution. The model-predicted displacements and the residuals derived from the nonlinear inversion are shown in Additional file 1.

\section{Inversion of slip distribution}

When the geometric parameters of the fault are determined, a linear relationship exists between slip (strike-slip and dip-slip components) on the fault plane and surface deformation, as shown in Eq. 1. In this paper, we used the SDM software developed by Wang et al. (2011, 2013) to invert the slip distribution on the fault plane.

$$
d_{\text {InSAR }}=G s+\varepsilon
$$

where $d_{\text {InSAR }}$ is the observed value at the surface, $G$ is the Green's function, $s$ is the slip on the fault plane, and $\varepsilon$ is the measurement error.

Since the fault plane is usually divided into many small patches, $s$ represents the slip on each sub-fault plane. In this paper, we set length and width of the fault to be 38 and $24 \mathrm{~km}$, respectively. The fault plane was subsequently discretized into 912 sub-fault elements, each measuring $1 \times 1 \mathrm{~km}^{2}$. In addition, to prevent oscillating solutions for the slip distribution, the relationship between slip on the sub-fault element and the InSAR observation must satisfy the following condition:

$$
\min \left[\left\|G s-d_{\text {InSAR }}\right\|^{2}+\alpha^{2}\|H s\|^{2}\right] \rightarrow 0
$$


Table 3 Geometrical parameters of seismogenic fault produced by inversion

\begin{tabular}{llllllllll}
\hline Longitude $\left({ }^{\circ} \mathrm{E}\right)$ & Latitude $\left({ }^{\circ} \mathrm{N}\right)$ & Strike $\left({ }^{\circ}\right)$ & Dip $\left({ }^{\circ}\right)$ & Rake $\left({ }^{\circ}\right)$ & Slip $(\mathbf{m})$ & Depth $(\mathbf{k m})$ & Length $(\mathbf{k m})$ & Width $(\mathbf{k m})$ & Magnitude $\left(M_{\mathrm{w}}\right)$ \\
\hline $77.806 \pm 0.1$ & $35.386 \pm 0.1$ & $96 \pm 2.6$ & $84 \pm 4.2$ & $-24 \pm 7.7$ & $4.6 \pm 1.0$ & $17.0 \pm 2.0$ & $20.0 \pm 2.6$ & $5.8 \pm 2.0$ & $6.6 \pm 0.3$
\end{tabular}

a The location (longitude and latitude) of the fault is indicated in the top-left corner

where \|\|$^{2}$ is the Euclidean norm, $H$ is the Laplacian constraint that limits fault smoothness, $s$ is the amount of slip in the underground fault plane to be calculated, $\alpha$ is a factor that defines fault smoothness, and $G s-d_{\text {InSAR }}$ is the residual of a fit to the fault dislocation.

During the inversion process, the CRUST 1.0 model was used to determine the regional crust stratification structure and calculate Green's function. For the sliding amount of adjacent patches, the stress drop smoothing constraint was applied because a constant stress drop is a more realistic approximation from a physical perspective.

The slip distribution obtained by the inversion is shown in Fig. 7. Gaps between the simulated values were filled using the kriging interpolation method, which is commonly used in geology.

According to the surface deformation distribution characteristics and deformation magnitude of the simulated and observed deformation fields in Fig. 6, the two fields show good consistency with a correlation of $90.1 \%$. This proves that the Okada elastic model can well explain the co-seismic deformation field of the Karakoram Pass earthquake. Quantitative analysis needs to be based on residual error distribution. The residual error values are mainly distributed on both sides of the fault and the edge of the deformation zone, with the values being mostly less than $10 \mathrm{~cm}$ and the maximum being $12.1 \mathrm{~cm}$. This shows that the residual error mainly might come from simplification of fault model and unwrapping error caused by excessive deformation gradient.

The co-seismic fault slip distribution shows that the co-seismic displacement is dominated by sinistral strikeslip accompanied by a small normal slip component. The rupture length along the direction of the strike reaches $24 \mathrm{~km}$. The co-seismic slip distribution was concentrated between 0 and $18 \mathrm{~km}$ in depth. The maximum slip was $81 \mathrm{~cm}$, which occurred at a depth of $8.5 \pm 0.5 \mathrm{~km}$, which shallower than the depth of derived from the uniform slip model $(17 \mathrm{~km})$, with projected ground location at lat. $35.36^{\circ} \mathrm{N}$ and long. $78.03^{\circ} \mathrm{E}$. As shown in Fig. $7 \mathrm{a}$, at about $30 \mathrm{~km}$ along the fault strike, the eastward displacement of the fault is obviously obstructed by a nearly vertical dip. The co-seismic slip is smaller below $18 \mathrm{~km}$ depth, which shows that this was a shallow-focus earthquake. The inverted dislocation model has a corresponding moment magnitude of $M_{\mathrm{w}} 6.5 \pm 0.11$, which is less than the values

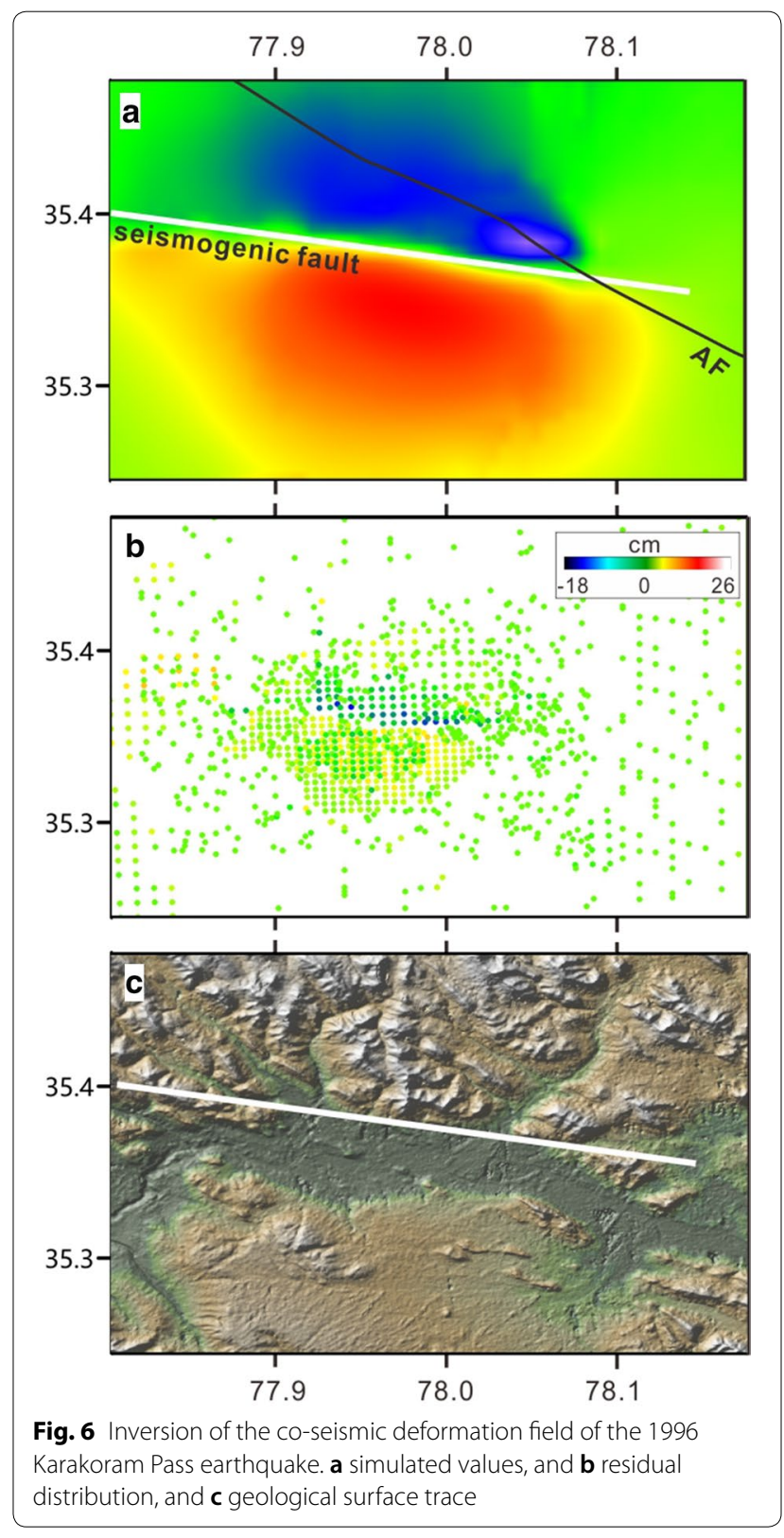

provided by the three seismological analyses (shown in Table 1). This might be related to the very long temporal baselines in the interferograms and the sparseness of the deformation field. 


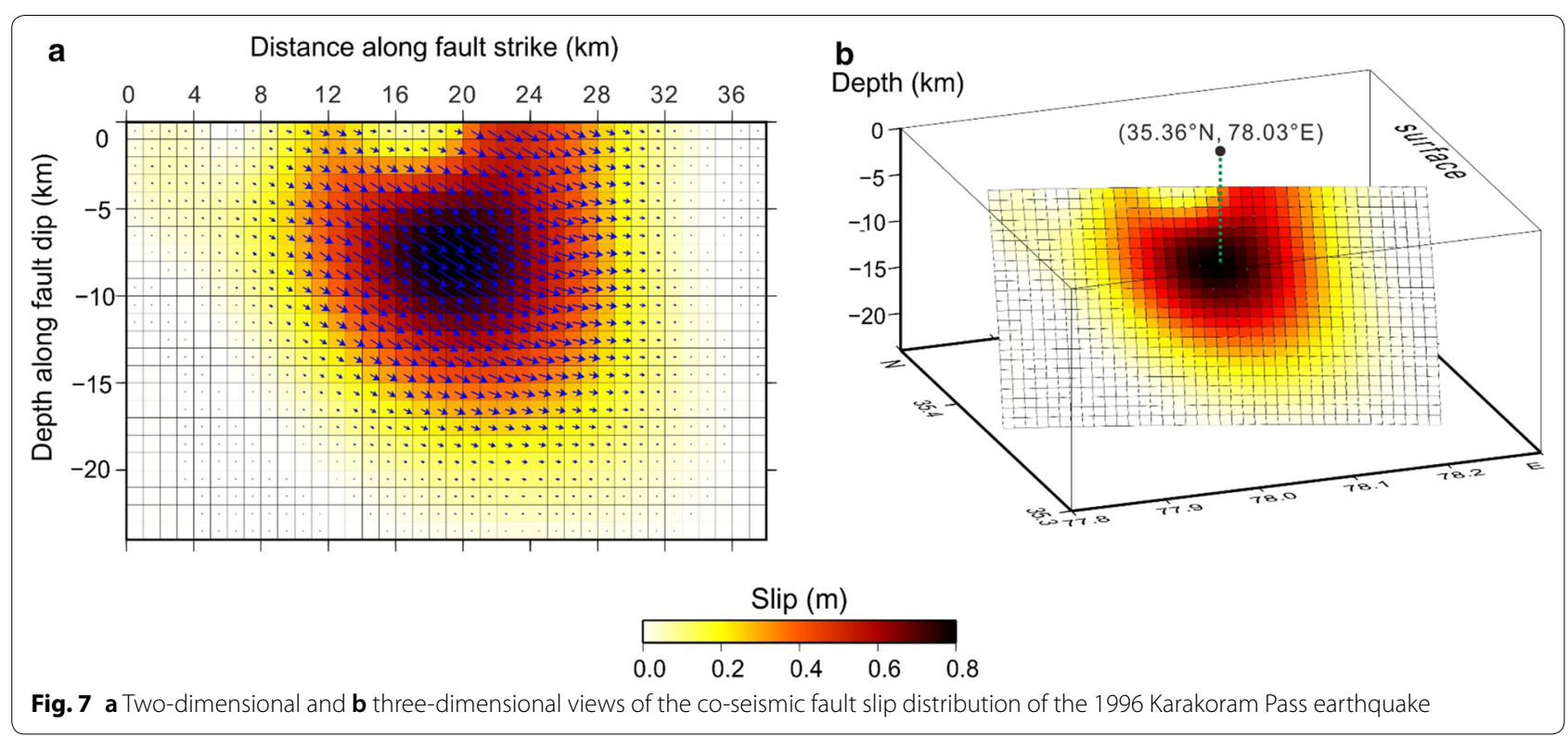

\section{Discussion}

\section{Uncertainty of co-seismic deformation field}

InSAR allows the seismology of remote areas with limited seismic networks to be examined. However, the available SAR image data for the Karakoram Pass earthquake are very limited; only 3 sets of interferometric pairs are available that span minimum and maximum time intervals of 841 and 1120 days, respectively. Therefore, the 3 interferometric deformation fields, which were used to invert the co-seismic slip distribution, include post-seismic deformation data for a 2.5 year period after the earthquake. Post-seismic deformation might be caused by residual slip of a seismogenic fault. Therefore, the co-seismic slip distribution should also contain some after-slip. However, because the magnitude of the main shock was not high, after-slip should be relatively small and should not affect the overall distribution of the co-seismic slip. The residual distribution map of the inversion results (Fig. 6b) exhibits fan-shaped over-fitting surrounding the stripshaped central area in the deformation zone, where the values are mostly less than $10 \mathrm{~cm}$ and the maximum being $12.1 \mathrm{~cm}$. The residual error mainly comes from simplification of fault model and unwrapping error caused by excessive deformation gradient. As shown in Fig. $4 a^{\prime}-c^{\prime}$, incoherence is the most serious in the mountainous region. Although incoherence caused by the long temporal baseline affect the InSAR results, the InSAR deformation field covers the near-field region of the epicenter well, thus the model-predicted InSAR deformation can account well for the observations in both the near- and the far-fields.

\section{Epicenter location}

Due to the scarcity of seismic stations in Asia in 1996 and crustal inhomogeneity in the Qinghai-Tibetan Plateau, the location of the Karakoram Pass earthquake epicenter as determined from seismic data was highly uncertain (Table 1). The largest discrepancy between the GCMT results and those from (Gao et al. 2005) was $38 \mathrm{~km}$. The inversion results presented in this paper show that the location of the co-seismic fault epicenter is $35.36^{\circ} \mathrm{N}$ and $78.03^{\circ} \mathrm{E}$ (Figs. 1, 7). This result deviate from the results provided by the three institutions to various degrees, with the smallest discrepancy from the USGS results and the largest discrepancy from Gao et al. (2005) results being 9.4 and $19.8 \mathrm{~km}$, respectively. These deviations might be attributed to three factors: the epicenter location obtained through seismological inversion was the location of the initial rupture; each institution used a different velocity structure for inversion; the QinghaiTibetan Plateau is characterized by crustal heterogeneity (Weston et al. 2012).

The maximum surface deformation caused by the Karakoram Pass earthquake is located at the intersection between the concealed secondary fault and the Ageledaban fault at the lowest elevation of the epicenter region. However, the inversion results show that there is overfitting in the alluvial valley. Therefore, one can deduce that some mass slides from the mountains on the north side of the fault were carried by thawing and flow of river water during summer. This mass deposited in the alluvial valley during the temporal baseline of the interferograms. The maximum surface deformation should be closer to 
the intersection between the concealed secondary fault and the Ageledaban fault.

The maximum co-seismic slip is located at a depth of $8.5 \pm 0.5 \mathrm{~km}$, which is a relatively shallow depth compared with other seismic structures. This shows that focal depths determined by InSAR are generally shallower than those determined through traditional seismological methods (Weston et al. 2012). Moreover, as the depth increases, the discrepancy increases. This is because the focal location determined through InSAR is calculated based on a slip distribution model, which is derived from a surface deformation field. For shallow source earthquakes, InSAR better constrains the spatial characteristics of faults compared to seismological inversion based on long-period body waves or surface wave data (Weston et al. 2012).

\section{Seismogenic fault}

After the Karakoram Pass earthquake, the focal mechanism solutions determined from teleseismic body wave data show that this earthquake was primarily a strike-slip rupture event. However, different solutions show large differences in the deformation distribution caused by this earthquake. USGS estimated the epicenter intensity at VIII with the long axis strike oriented east-west. Based on the GCMT focal mechanism solution, Ge (1997) proposed that the seismogenic fault should be a secondary transverse fault related to the Karakoram fault. Luo et al. (2003) proposed that the seismogenic fault was the Linjitang fault (LF) in the Karakoram fault zone, with the maximum epicenter intensity VIII, and the long axis strike was oriented NW, which is consistent with the strike in the seismogenic structure. The simulated deformation map of the Karakoram Pass earthquake obtained based on InSAR technology and SDM method shows that surface deformation caused by this earthquake exhibits a regularly shaped ellipse along the EW direction and asymmetric distributed on both sides of a concealed fault zone. These findings are relatively consistent with the USGS shake map (https://earthquake.usgs.gov/earth quakes/eventpage/usp0007t7m/executive).

The co-seismic slip distribution image shows co-seismic displacement being dominated by sinistral strike-slip with a small normal slip component. The co-seismic slip distribution was concentrated at a depth ranging from 0 to $18 \mathrm{~km}$, with the maximum slip reaching $81 \mathrm{~cm}$. The obtained results show that the Ageledaban fault is not a seismogenic fault. Rather, the seismogenic fault is a concealed secondary fault with $96^{\circ}$ strike, $84^{\circ}$ dip, and $-24^{\circ}$ rake. Because of the limited amount of data, the geological structure of the concealed fault and its relationship with the surrounding deep tectonic structures should be investigated further.
Based on the inversion results for slip distribution, one can deduce that the fault caused by this earthquake was affected by the Ageledaban fault during the slip process. It is presumed that when the south side of the seismogenic fault slid eastward and made contact with the Ageledaban fault, slip energy was absorbed by the deep Ageledaban fault, and affected by gravity, it produced partial normal dip-slip. This also explains why the fringes on the south side of the fault diverge to the southeast.

\section{Tectonic movement of the epicenter region}

Shallow earthquakes are generally related to tectonic activity. Being a subduction passive-continental margin in an orogenic belt, the Karakoram formed as a part of an ancient continent, which was divided by rift basins over different epochs. The Karakoram Mesozoic continental-margin basin was uplifted during the Neogene and formed a series of NW-strike compression-shear faults and linear folds after undergoing multiple episodes of tectonic movement (Luo et al. 2004). Due to the nearly $\mathrm{N}-\mathrm{S}$ compressional stress, the Karakoram fault zone has dextral strike-slip characteristics, with multiple strikeslip earthquakes occurring in the fault zone (Valli et al. 2007).

The tectonic strain field in the epicenter region (Fig. 8) was calculated using the least square collocation method (Zhang et al. 2004) based on 33 GPS velocity (Fig. 1) values close to the epicenter measured from 1997 to 2015 (Zheng et al. 2017). The results show that this high-strain zone represents post-seismic deformation from the 1996 earthquake, which is consistent with Wang and Wright (2012), and the Karakoram strike-slip fault zone has undergone a complex tectonic deformation process. The continuous northward movement of the Indian plate is causing a continual uplift of the Qinghai-Tibetan Plateau. This is accompanied by coupling deformation and northward migration of the lithospheric upper mantle, causing accumulation of significant residual mass. Meanwhile, due to the constraining role of the rigid Tarim basin, many surface uplifts and depressions have formed in the Karakoram fault zone (Xu et al. 2014). The principal strain rate shows a decreasing trend on both sides of the Karakoram strike-slip fault. In addition, positive and negative surface expansion rates are present. Under the assumption of volume conservation, a negative value indicates vertical expansion or thickening, and a positive value indicates vertical contraction or thinning. It is evident from Fig. $8 \mathrm{~b}$ that the expansion rate is primarily positive on the north side of the epicenter region and negative on the south side, meaning the north side is experiencing crustal thinning, while the south side is undergoing crustal thickening. This means that the 

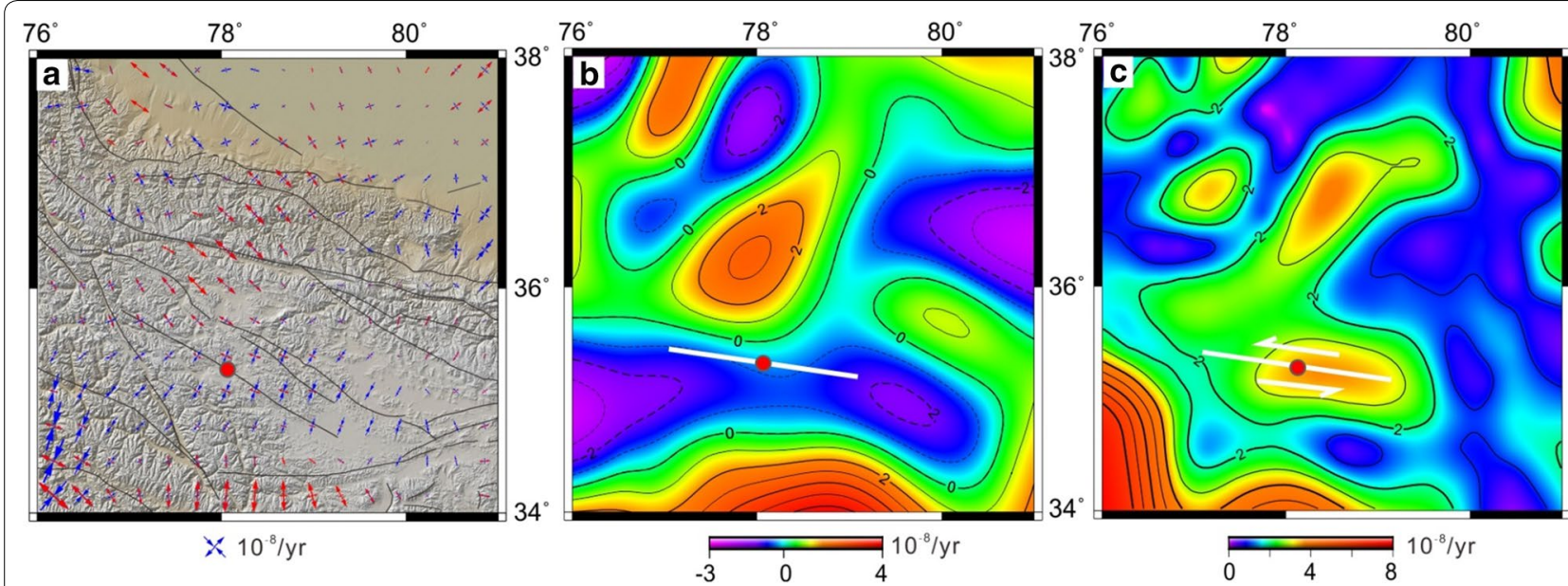

Fig. 8 Tectonic strain field in the epicenter region: a principal strain rate field; blue and red bars indicate the principal compressional and extensional strain rates, respectively; $\mathbf{b}$ dilatational strain rate field; and $\mathbf{c}$ maximum shear strain rate field: the white line is the seismogenic fault

Karakoram Pass earthquake occurred in a strain gradient zone. In addition, as shown in Fig. 8c, the epicenter is located in a region with the largest value of the maximum shear strain rate field, and the shape of the field in this region is consistent with the strike of the seismogenic fault. Although these results reflect the strain conditions after the 1996 earthquake, they also indicate from the side that left-lateral component of the earthquake may have occurred to offset the accumulated strain energy. This indicates that the Kongur system on the north side of the Karakoram fault zone is extensional, but so is the central part, which might explain the formation of a basin in the middle part of the fault zone.

\section{Conclusion}

The Ms7. 1 Karakoram Pass earthquake on November 19, 1996 occurred at the northwest of the QinghaiTibet Plateau, in an area with harsh natural conditions and very weak monitoring capability of the seismic network. We obtained the co-seismic deformation field of the earthquake by using the ERS1/2 SAR data and InSAR technology. With the deformation field as a constraint, the geometric parameters of seismogenic fault were inversed nonlinearly based on Okada dislocation model, and the slip distribution on the fault plane was inversed linearly using SDM method. The main conclusions are as follows:

1. Most of the deformation caused by this earthquake is concentrated within an area measuring $18 \times 9 \mathrm{~km}^{2}$, with the maximum LOS shortening in the southern side $24.6 \mathrm{~cm}$. The maximum LOS lengthening in the northern side is approximately $18.5 \mathrm{~cm}$. The inversion result shows that the location of the co-seismic rupture centroid is $\left(78.03^{\circ} \mathrm{E}, 35.36^{\circ} \mathrm{N}\right)$, and the calculated moment magnitude is Mw6.5, which is slightly smaller than the magnitude released by other methodologies.

2. The seismogenic fault is a concealed secondary fault with $96^{\circ}$ strike, $84^{\circ}$ dip, and $-24^{\circ}$ rake, which is located in the movement range of the Ageledaban fault. The co-seismic displacement is dominated by sinistral strike-slip accompanied by a small normal slip component. The slip distribution was concentrated between 0 and $18 \mathrm{~km}$ in depth. The maximum slip was $81 \mathrm{~cm}$, which occurred at a depth of $8.5 \pm 0.5 \mathrm{~km}$.

3. The Karakoram strike-slip fault zone has undergone a complex tectonic deformation process: the north side of the epicenter region is experiencing crustal thinning, while the south side is undergoing crustal thickening. This indicates that tension also exists in the central part of the Karakoram fault zone.

\section{Supplementary information}

Supplementary information accompanies this paper at https://doi. org/10.1186/s40623-019-1089-4.

Additional file 1. The model-predicted displacements (a) and the residuals (b) derived from the non-linear inversion.

\section{Abbreviations}

ERS: European Space Agency; InSAR: Interferometric synthetic aperture radar; CST: China Standard Time; GCMT: Global Centroid Moment Tensor Project; USGS: United States Geological Survey; GPS: Global Positioning System; NASA: National Aeronautics and Space Administration; LOS: Line of sight; AZ: Azimuth; SDM: Steepest descent method. 


\section{Acknowledgements}

Appreciate for SAR data provided by ESA, ENVI/SARScape (trial version) provided by Esri China, and SDM program provided by professor Wang Rongjiang. Thanks to professor Sun Jianbao for his helpful advice. We also thank the Editor and two anonymous reviewers for their constructive comments.

\section{Authors' contributions}

$J Q$ processed SAR data and analyzed the results. $L J$ designed this work and supplemented the conclusions. LL completed calculation and mapping of GPS data, and CL provided technical support and useful advice for InSAR processing. All authors read and approved the final manuscript.

\section{Funding}

This paper was supported by the National Key Research and Development Program of China (2017YFC1500102) and the National Natural Science Foundation of China (No. 41604015).

\section{Availability of data and materials}

The ERS-1/2 SAR data are provided by European Space Agency (ESA) through http://esar-ds.eo.esa.int/sxcat, the SRTM DEM data can be obtained from https ://earthexplorer.usgs.gov/, and the SDM program provided by Professor Rongjiang Wang (https://www.gfz-potsdam.de/en/section/physics-of-earthquake s-and-volcanoes/data-products-services/downloads-software/).

\section{Ethics approval and consent to participate}

Not applicable.

\section{Consent for publication}

Not applicable.

\section{Competing interests}

The authors declare that they have no competing interests.

Received: 9 May 2019 Accepted: 11 October 2019

Published online: 22 October 2019

\section{References}

Chen JB (2008) Research on seismotectonic features in Xinjiang. Dissertation, China Earthquake Administration Lanzhou Institute of Seismology. (in Chinese)

Gao GY, Wen HP, Nie XH (2005) Analysis of focal-mechanism solution of moderately strong earthquakes in Xinjiang from 1991 to 2002. Earthquake 25(1):81-87 (in Chinese)

Ge SM (1997) Two Strong Earthquakes occurred in Xinjiang in 1996. Northwestern seismological J 19(1):89-90 (in Chinese)

Ghiglia DC, Romero LA (1994) Robust two-dimensional weighted and unweighted phase unwrapping that uses fast transforms and iterative methods. JOSA A 11(1):107-117

Goldstein RM, Werner CL (1998) Radar interferogram filtering for geophysical applications. Geophys Res Lett 25(21):4035-4038

Kobayashi T (2017) Earthquake rupture properties of the 2016 Kumamoto earthquake foreshocks ( $\mathrm{M} \mathrm{j} .5$ and $\mathrm{M} \mathrm{j}$ 6.4) revealed by conventional and multiple-aperture InSAR. Earth Planets Space 69(1):7. https://doi. org/10.1186/s40623-016-0594-y

Li HB, Valli F, Xu ZQ, Yang JS, Tapponnier P, Lacassin R, Chen SY, Qi XX, Chevalier ML (2006) Deformation and tectonic evolution of the Karakorum fault, western Tibet. Geol China 33(2):239-255 (in Chinese)

Li HB, Valli F, Arnaud N, Chen SY, Xu ZQ, Tapponnier P, Lacassin R, Si JL, Qiu ZL (2008) Rapid uplifting in the process of strike-slip along the Karakorum fault zone in western Tibet: evidence from Ar-40/Ar-39 thermochronology. Acta Petrologica Sinica 24(7):1552-1566 (in Chinese)

Ji LY, Liu CJ, Xu J et al (2017) InSAR observation and inversion of the seismogenic fault for the 2017 Jiuzhaigou MS7.0 earthquake in China. Chin J Geophys 60(10):4069-4082

Liu C, Ji L, Zhu L, Zhao C (2018) InSAR-constrained interseismic deformation and potential seismogenic asperities on the Altyn Tagh fault at $91.5-95^{\circ} \mathrm{E}$, Northern Tibetan Plateau. Remote Sens 10(6):943
Luo FZ, Qu YJ, Wang J (2003) Study on the Ms7.1 earthquake at the mouth of Kalakunlun MT. in Hetian, Xingjiang on nov. 19, 1996. Inland Earthq 17(1):34-39 (in Chinese)

Luo JH, Che ZC, Li JL (2004) Structural features of the Jurassic basins in western China and middle Asia. Scientia Geologica Sin 35(4):404-413

Marquardt DW (1963) An algorithm for least-squares estimation of nonlinear parameters. J Soc Ind Appl Math 11(2):431-441

Massonnet D, Briole P, Arnaud A (1995) Deflation of Mount Etna monitored by spaceborne radar interferometry. Nature 375(6532):567

Matte P, Tapponnier P, Arnaud N, Bourjot L, Avouac JP, Vidal P, Qing L, Yusheng P, Yi W (1996) Tectonics of Western Tibet, between the Tarim and the Indus. Earth Planet Sci Lett 142(3-4):311-330

Okada Y (1985) Surface deformation due to shear and tensile faults in a halfspace. Bull Seismol Soc Am 75(4):1135-1154

Pan JW, Li HB, Woerd J, Sun ZM, Pei JL, Si JL, Qiu ZL (2009) Tectonic geomorphology and active tectonics in north eastern Pamir, northwest margin of Qinghai Tibet Plateau. Quat Sci 29(3):586-598

Pan GT, Wang LQ, Zhang WP, Wang BD (2013) Geotectonic map and instructions for Qinghai-Tibet plateau and its neighboring areas. Geological Publishing House, Beijing (in Chinese)

Qiu J, Qiao X (2017) A study on the seismogenic structure of the 2016 Zaduo, Qinghai Ms6. 2 earthquake using InSAR technology. Geodesy Geodyn 8(5):342-346

Searle MP, Weinberg RF, Dunlap WJ (1998) Transpressional tectonics along the Karakoram fault zone, northern Ladakh: constraints on Tibetan extrusion. Geol Soc Lond Spec Publ 135(1):307-326

Sun JB, Shi YL, Shen ZK, Xu XW, Liang F (2007) Parameter inversion of the 1997 Mani earthquake from Insar co-seismic deformation field based on linear elastic dislocation model-II. Slip distribution inversion. Chin J Geophys 50(5):1190-1198

Teshebaeva K, Sudhaus H, Echtler H, Schurr B, Roessner S (2014) Strain partitioning at the eastern Pamir-Alai revealed through SAR data analysis of the 2008 Nura earthquake. Geophys J Int 198(2):760-774

Valli F, Arnaud N, Leloup PH, Sobel ER, Mahéo G, Lacassin R, Guillot S, Li H, Tapponnier P, Xu Z (2007) Twenty million years of continuous deformation along the Karakorum fault, western Tibet: a thermochronological analysis. Tectonics 26, TC4004

Wang H, Wright TJ (2012) Satellite geodetic imaging reveals internal deformation of western Tibet. Geophys Res Lett 39:L07303

Wang XL, Lu X, Liu B, Li J, Liu DQ (2009) Study on Present-day Vertical Crust Movement and Seismic Activity in Xinjiang Area.J Geod. Geodyn 29(6):22-27,31 (in Chinese)

Wang R, Schurr B, Milkereit C, Shao Z, Jin M (2011) An improved automatic scheme for empirical baseline correction of digital strong-motion records. Bull Seismol Soc Am 101(5):2029-2044

Wang R, Parolai S, Ge M, Jin M, Walter TR, Zschau J (2013) The 2011 M w 9.0 Tohoku earthquake: comparison of GPS and strong-motion data. Bull Seismol Soc Am 103(2B):1336-1347

Wen YM, Xu CJ, Liu Y (2015) The 2007 Ali earthquake inversion from ascending and descending InSAR observations. Acta Geodaetica et Cartographica Sinica 44(6):649-654 (in Chinese)

Weston J, Ferreira AM, Funning GJ (2012) Systematic comparisons of earthquake source models determined using InSAR and seismic data. Tectonophysics 532:61-81

Xu WM, Chen S, Shi L (2014) Seismic activity and gravity anomaly characteristics of Yutian in Xinjiang and surrounding regions. Earth Sci J China Univ Geosci 39(12):1831-1841 (in Chinese)

Zhang X, Jiang ZS, Wang Q, Wang SC, Cui DX, Zhang XL (2004) Tectonic deformation features of the northern Tibetan plateau and their relationship to strong earthquakes. Prog Geophys 9(2):363-371 (in Chinese)

Zhao Q, Wang SX, Jiang FY, Li N (2017) Coseismic deformation field and fault slip distribution of the 2016 Qinghai Menyuan Mw5.9 earthquake from InSAR measurement. Earthquake 37(2):95-105 (in Chinese)

Zheng G, Wang H, Wright TJ, Lou Y, Zhang R, Zhang W, Shi C, Huang J, Wei N (2017) Crustal deformation in the India-Eurasia collision zone from 25 years of GPS measurements. J Geophys Res Solid Earth 122(11):9290-9312

\section{Publisher's Note}

Springer Nature remains neutral with regard to jurisdictional claims in published maps and institutional affiliations. 